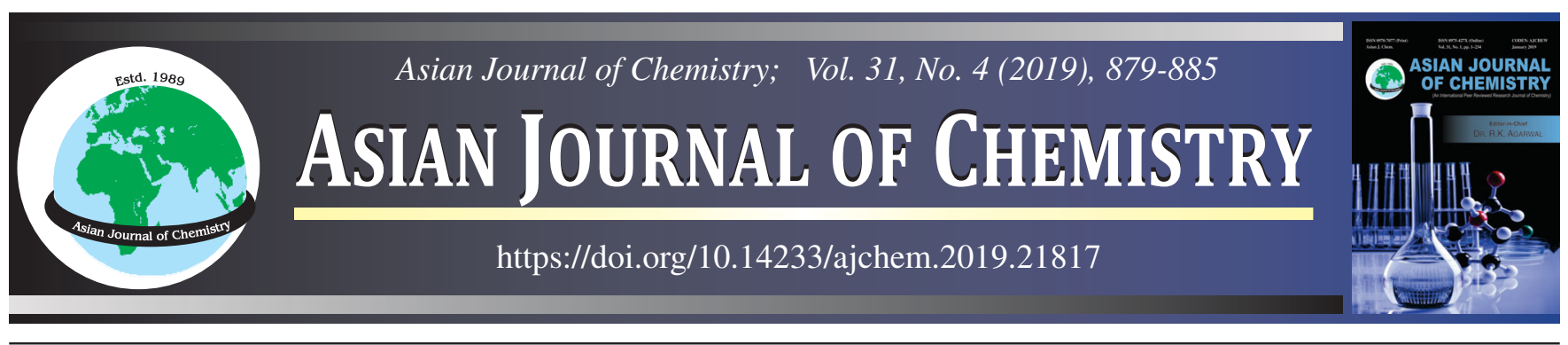

\title{
Synthesis, Optical, Morphological and Magnetic Properties of Hematite Nanorods in Deep Eutectic Solvent with its Antibacterial and Photocatalytic Applications
}

\author{
Swathi Pon SAKthi Sri V. ${ }^{1}$, A. Vijayakumar ${ }^{2}$ and Mary George ${ }^{1, *}$
}

${ }^{1}$ Department of Chemistry, Stella Maris College, Chennai-600086, India

${ }^{2}$ Department of Chemistry, Loyola College, Chennai-600094, India

*Corresponding author: E-mail: maryge@gmail.com

Received: 15 November 2018;

Accepted: 3 January 2019;

Published online: 27 February 2019;

AJC-19301

Deep eutectic solvent comprising of choline chloride and $\mathrm{D}(+)$-glucose was synthesized by mixing in the molar ratio $2: 1$. Iron oxide nanoparticles were successfully synthesized by co-precipitation method. Deep eutectic solvent consisting of $\mathrm{D}(+)$-glucose acts as a promising reducing agent for the synthesis of iron oxide nanoparticles. Direct optical band gap of iron oxide nanoparticles was found to be $2.262 \mathrm{eV}$. Powder X-ray diffraction technique was used to identify the crystalline phases. Surface morphology analysis by Field emission scanning electron microscopy and high resolution transmission electron microscopy confirmed the rod shape structure of the iron oxide nanoparticles. Selected area electron diffraction pattern revealed the identity of lattice planes with the XRD data. The antibacterial and photocatalytic activities of the iron oxide nanoparticles were also studied. The synthesized iron oxide nanoparticles showed appreciable antibacterial and photocatalytic activities

Keywords: Deep eutectic solvent, Iron oxide nanoparticles, Antibacterial activity, Dye degradation, Photo-Fenton reaction.

\section{INTRODUCTION}

Deep eutectic solvent is a mixture of two or more compounds which has a melting point lower than that of its individual components. Organic halide salts such as choline chloride with an organic compound acts as hydrogen bond donor (HBD) and these HBD can form a hydrogen bonding with compounds such as amides, amines, alcohols, carboxylic acids and many more [1]. Deep eutectic solvent has many unique properties such as high viscosity, high thermal stability and low vapour pressure which makes them use in various applications [2].

Iron oxide exists in different phases like hematite $\left(\alpha-\mathrm{Fe}_{2} \mathrm{O}_{3}\right)$, magnetite $\left(\mathrm{Fe}_{3} \mathrm{O}_{4}\right)$, akaganeite $\left(\beta-\mathrm{Fe}_{2} \mathrm{O}_{3}\right)$ and maghemite $\left(\gamma-\mathrm{Fe}_{2} \mathrm{O}_{3}\right)$ [3]. Among the phases, hematite $\left(\alpha-\mathrm{Fe}_{2} \mathrm{O}_{3}\right)$ is the most stable iron oxide with n-type semiconducting properties and optical band gap of $2.1 \mathrm{eV}$. It has been widely used in catalysts, gas sensors and magnetic devices. Due to its high electrical conductivity, sensitivity and large surface area, hematite is used as an efficient photocatalyst [4]. There are various chemical approaches for the synthesis of iron oxide nanoparticles such as coprecipitation, sol-gel and forced hydrolysis, hydrothermal, surfactant mediated/template synthesis, micro-emulsion, electrochemical and laser pyrolysis. Among these, co-precipitation technique is the easiest and most efficient chemical method by which a larger amount of nanoparticles can be synthesized [5].

The development of new resistant strains of bacteria to present antibiotics has become a serious issue in public health. In order to overcome this issue development of new bactericides from various sources is been emerging by researchers [6]. The recent development in the field of nanotechnology has made way for synthesizing alternative antimicrobial agents [7]. Dyes represent a class of organic pollutants which are highly carcinogenic. The wastewater effluents from industries such as textile, leather goods, food, plastics, cosmetics, etc. contaminated with such organic pollutants when released into the environment causes aesthetic pollution and disturbs the ecosystem. Among the most environmental remediation techniques, such as adsorption, ultrafiltration, reverse osmosis, etc. photocatalytic degradation of such pollutants stands out to be much important since it mineralizes the harmful chemicals without any secondary disposal requirement [4].

This is an open access journal, and articles are distributed under the terms of the Creative Commons Attribution-NonCommercial-ShareAlike 4.0 (CC BY-NC-SA 4.0) International License which allows readers to freely read, download, copy, distribute, print, search, or link to the full texts of its articles and to use them for any other lawful non-commercial purpose as long as the original source is duly acknowledged. 
Photo-Fenton's reaction is a homogeneous catalytic oxidation process using a mixture of hydrogen peroxide and ferrous ions. The use of light energy in Fenton's process accelerates dye decolourization as it influences the direct formation of hydroxide radicals [8]. The hydroxide radicals having strong oxidation potential can completely degrade organic pollutant to $\mathrm{CO}_{2}$ and $\mathrm{H}_{2} \mathrm{O}$ [9]. Photocatalytic degradation has the potential to use energy from the sun to degrade dyes in solar light conditions; this ability makes degradation comparably cheap when sunlight can be used [10]. In the present investigation, hematite $\left(\alpha-\mathrm{Fe}_{2} \mathrm{O}_{3}\right)$ nanorods were synthesized by co-precipitation method and optical, morphological and magnetic properties were analyzed. The as characterized nanomaterial has been used for the remediation of organic pollutant and disease causing microbes.

\section{EXPERIMENTAL}

All the chemicals (HiMedia, India ) used are of analytical grade and used as received without further purification.

Synthesis of deep eutectic solvent: The mixture of choline chloride and $\mathrm{D}(+)$-glucose in the molar ratio 2:1 was magnetically stirred at $600 \mathrm{rpm}$ and heated at $80{ }^{\circ} \mathrm{C}$ for a period of 120 min until a homogenous transparent colourless liquid was obtained [11].

Synthesis of iron oxide $\left(\alpha-\mathrm{Fe}_{2} \mathrm{O}_{3}\right)$ nanoparticles: Iron oxide nanoparticles were synthesized according to the method of Chen et al. [12] with slight modification. Briefly, $6.488 \mathrm{~g}$ ( $40 \mathrm{mmol}) \mathrm{FeCl}_{3}$ and $4.0153 \mathrm{~g}(20 \mathrm{mmol})$ pulverized $\mathrm{FeCl}_{2} \cdot 4 \mathrm{H}_{2} \mathrm{O}$ were added to $40 \mathrm{~g}$ of deep eutectic solvent made of choline chloride: $\mathrm{D}(+)$-glucose, and stirred at $600 \mathrm{rpm}$ and $80{ }^{\circ} \mathrm{C}$ for $20 \mathrm{~min}$. Eventually, $2.4052 \mathrm{~g}$ (42.86 mmol) $\mathrm{KOH}$ was added and stirred for another $30 \mathrm{~min}$. The brownish black precipitate thus obtained was washed several times with acetone and distilled water and dried at room temperature for $5 \mathrm{~min}$.

Characterization: Jasco UV-Vis Spectrophotometer V-750 in the wavelength range from 200 to $800 \mathrm{~nm}$ with the scan speed of $1000 \mathrm{~nm} / \mathrm{min}$ was used to study the formation and band gap of iron oxide nanoparticles. The X-ray diffraction analysis was carried out using a BRUKER D8 Advance powder $\mathrm{X}$-ray diffractometer with $\mathrm{CuK} \alpha$ radiation at $30 \mathrm{kV}$ and $20 \mathrm{~mA}$. The morphology and texture of iron oxide nanoparticles was analyzed using model JSM 6701F, Jeol, Japan. Transmission electron microscopy image was recorded using Jeol/JEM 2100 with an accelerating voltage of $200 \mathrm{kV}$. The point resolution is $0.23 \mathrm{~nm}$ and lattice resolution is $0.14 \mathrm{~nm}$. Vibrating sample magnetometer (VSM) measurements was recorded with maximum magnetic field 2.5 T using Model 7407, Lakeshore, USA.

Antibacterial activity: Antibacterial activity was performed using standard disc diffusion method [13] against the following test organisms Enterobacter aerogenes (111), Staphylococcus epidermidis (3615), Escherichia coli (25922), Vibrio parahaemolyticus (451), Proteus vulgaris (1771), Klebsiella pneumonia (ATCC1706), Yersinia enterocolitica (840), Salmonella typhimurium (1251) and Staphylococcus aureus (96). $20 \mathrm{~mL}$ of Muller Hinton agar (MHA) medium were transferred to each petri plates. The 24 hour test culture were swabbed using sterile cotton swabs on the solidified media and allowed to dry for $20 \mathrm{~min}$. The tests were conducted using
$0.75,1$ and $1.25 \mathrm{mg} /$ disc of iron oxide nanoparticles dispersed in sterile distilled water. Choline chloride and $\mathrm{D}(+)$-glucose were loaded of $1 \mathrm{mg} / \mathrm{disc}$. The sterile impregnated discs with iron oxide nanoparticles, choline chloride and $\mathrm{D}(+)$-glucose were placed on the agar surface with framed forceps and gently pressed down to ensure complete contact of the disc with agar surface. The loaded discs were left undisturbed for $30 \mathrm{~min}$ at room temperature for compound diffusion. Streptomycin 25 $\mu \mathrm{g} / \mathrm{disc}$ and blank discs impregnated with distilled water were used as positive and negative control, respectively. The plates were incubated at $37{ }^{\circ} \mathrm{C}$ for $18 \mathrm{~h}$. Zones of inhibition were measured using an antibiotic zonescale-C.

Photocatalytic activity: Solar photocatalytic experiments were performed in a borosil glass beaker containing $100 \mathrm{~mL}$ of $10 \mathrm{ppm}$ Congo red aqueous solution, $2 \mathrm{~mL}$ of $30 \% \mathrm{H}_{2} \mathrm{O}_{2}$ and $100 \mathrm{mg}$ iron oxide nanoparticles. The solutions were kept in dark for $15 \mathrm{~min}$ to attain adsorption equilibrium and then irradiated under direct sunlight radiation on a sunny day in the month of May at Chennai, India (GPS coordinates: $13^{\circ} 02^{\prime}$ $29.40^{\prime \prime} \mathrm{N}$ and $80^{\circ} 15^{\prime} 7.80^{\prime \prime} \mathrm{E}$ ) between $1 \mathrm{pm}$ and $4 \mathrm{pm}$. For every $15 \mathrm{~min}$, an aliquot of $5 \mathrm{~mL}$ was taken and centrifuged to eliminate the catalyst. The rate of degradation of Congo red dye was measured using UV-visible spectrophotometer at 497 nm.

\section{RESULTS AND DISCUSSION}

UV-visible spectroscopy analysis: The as-prepared sample was characterized for its electronic structure by diffuse reflectance UV-visible studies. From literature, it is reported that the diffuse reflectance (DR) UV-visible spectrum of iron based hydroxides/oxides can be divided into four regions based on absorptions; ligand to metal charge transfer $(250-400 \mathrm{~nm})$ along with contribution of $\mathrm{Fe}^{3+}$ ligand field transition $(290-310 \mathrm{~nm})$, pair excitation process $(400-600 \mathrm{~nm})$ of magnetically coupled $\mathrm{Fe}^{3+}$ ions and two strong absorption bands near 640 and 900 $\mathrm{nm}$ of ligand field transitions of $\mathrm{Fe}^{3+}$ cation in octahedral environment [14].

A broad band from 230 to $420 \mathrm{~nm}$ was observed (Fig. 1a), which is attributed to the ligand to metal charge transfer (direct transitions) and partly from the contributions of $\mathrm{Fe}^{3+}$ ligand field transition ${ }^{6} \mathrm{~A}_{1}-{ }^{4} \mathrm{~T}_{1}\left({ }^{4} \mathrm{P}\right),{ }^{6} \mathrm{~A}_{1}-{ }^{4} \mathrm{E}\left({ }^{4} \mathrm{D}\right),{ }^{6} \mathrm{~A}_{1}-{ }^{4} \mathrm{~T}_{2}\left({ }^{4} \mathrm{D}\right)$ and ${ }^{6} \mathrm{~A}_{1}-{ }^{4} \mathrm{E}\left({ }^{4} \mathrm{G}\right)$. The broad hump-like shoulder in the visible wavelength region of $480-580 \mathrm{~nm}$ is assigned to the pair excitation proc-esses ${ }^{6} \mathrm{~A}_{1}\left({ }^{6} \mathrm{~S}\right)+{ }^{6} \mathrm{~A}_{1}\left({ }^{6} \mathrm{~S}\right)$ to ${ }^{4} \mathrm{~T}_{1}\left({ }^{4} \mathrm{G}\right)-{ }^{4} \mathrm{~T}_{1}\left({ }^{4} \mathrm{G}\right)[14,15]$. This double excitation process is responsible for the red colour of $\alpha-\mathrm{Fe}_{2} \mathrm{O}_{3}$ phase [14]. The shape of the synthesized material plays a vital role in determining the degree of transition [15]. The investigations from the UV-visible spectrum of prepared sample furnished evidence for the shape-dependent optical properties. The direct optical band gap is determined by fitting the absorption values to the direct transition Tauc Mott plot equation by extrapolating the linear portions of the curves to absorption equal to zero as shown in Fig. $1 b$.

$$
\alpha \mathrm{h} v=\mathrm{A}\left(\mathrm{h} v-\mathrm{E}_{\mathrm{g}}\right)^{1 / 2}
$$

where $\alpha$ is the optical absorption coefficient, $h v$ is the photon energy, $\mathrm{E}_{\mathrm{g}}$ is the direct optical band gap, and $\mathrm{A}$ is a constant. The band gap was found to be $2.262 \mathrm{eV}$, thus indicating the as 

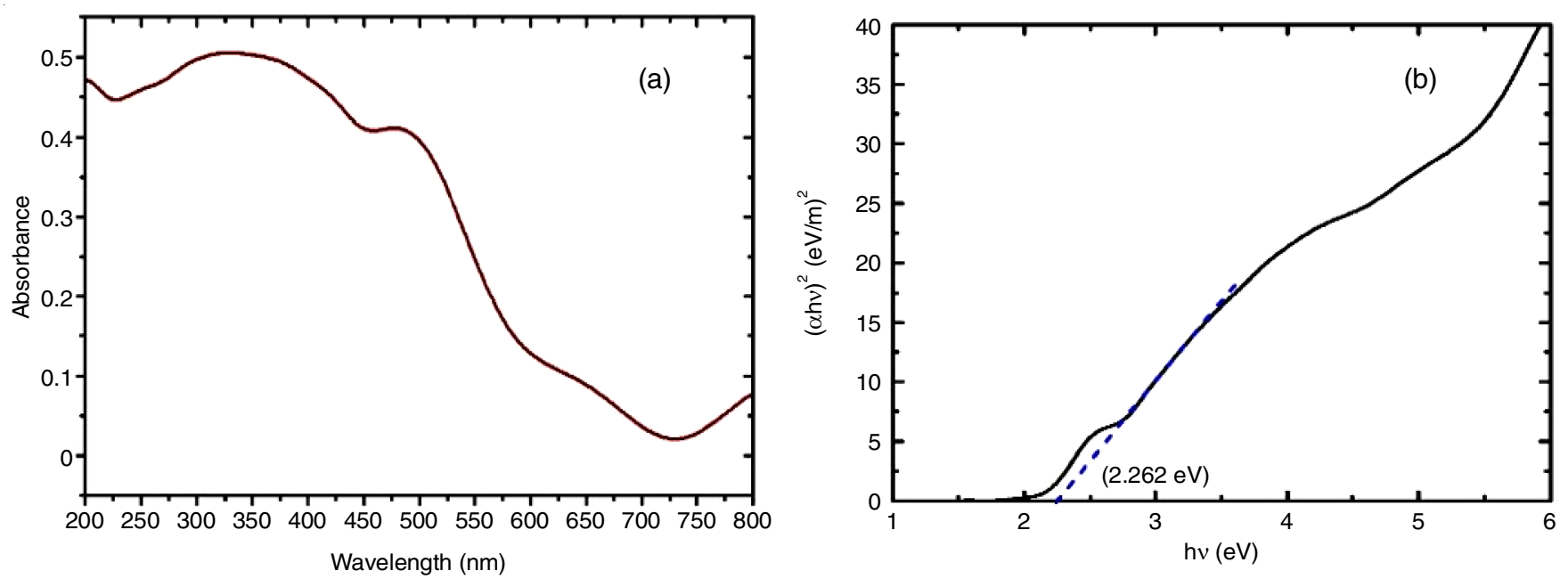

Fig. 1. (a) UV-visible spectrum of iron oxide nanoparticles (b) Direct optical energy band gap of iron oxide nanoparticles

synthesized nanorods behaves as semiconductors and can be used as efficient photocatalyst.

X-Ray diffraction analysis: The purity and crystallinity of as-prepared sample was examined using powder XRD measurements. Fig. 2 shows the XRD pattern of as-prepared iron oxide nanoparticles. The crystallite size of the particles was calculated using Scherrer's equation:

$$
\mathrm{D}=\frac{\mathrm{K} \lambda}{\beta \cos \theta}
$$

where, $\mathrm{D}=$ crystalline size, $\lambda=\mathrm{X}$-ray wavelength, $\mathrm{K}=$ shape factor, $\beta=$ full line width at the half-maximum elevation of the main intensity peak and $\theta=$ Bragg angle.

The average crystallite size was estimated to be 23.27 $\mathrm{nm}$. It is evident that the peaks at $2 \theta=26.74^{\circ}, 33.9^{\circ}, 35.21^{\circ}$, $39.26^{\circ}, 52.01^{\circ}, 55.872^{\circ}, 61.21^{\circ}$ and $64.33^{\circ}$ corresponds to (012), (104), (110), (113), (024), (116), (214), (300) indices. This can be indexed to a rhombohedral phase (hematite $\alpha-\mathrm{Fe}_{2} \mathrm{O}_{3}$, JCPDS No. 33-664). The strong and sharp diffraction peaks indicates good crystallinity of the synthesised nanoparticles.

Field emission scanning electron micrograph analysis (FESEM): The FESEM images (Fig. 3a-b) showed mono dispersed

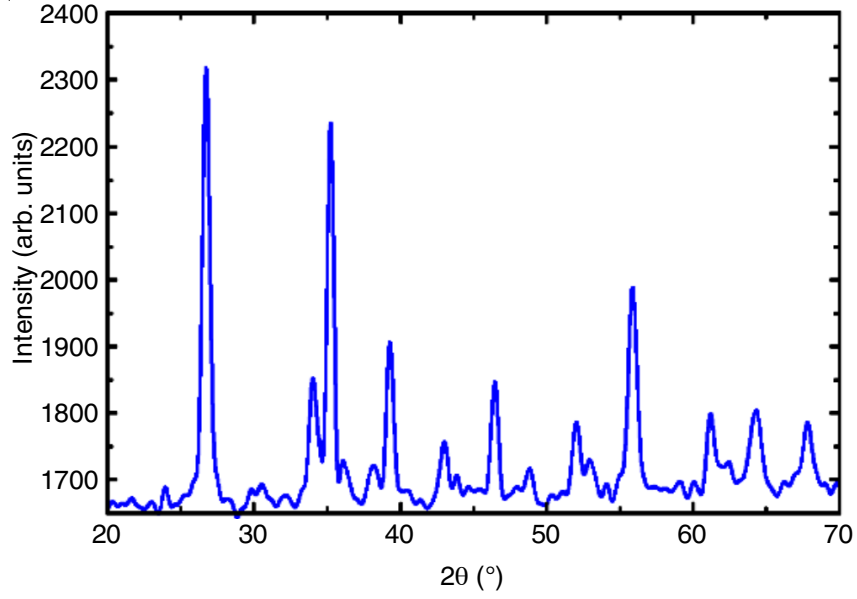

Fig. 2. XRD pattern of iron oxide nanoparticles

uniform rod shaped particles with an average diameter of 27 $\mathrm{nm}$. The average grain size of as-synthesised iron oxide nanoparticles obtained by FESEM correlates with the average crystallite size obtained in XRD studies.

Elemental mapping was analyzed using energy dispersive $\mathrm{X}$-ray (EDX) spectrometer. EDX spectrum is depicted in Fig.
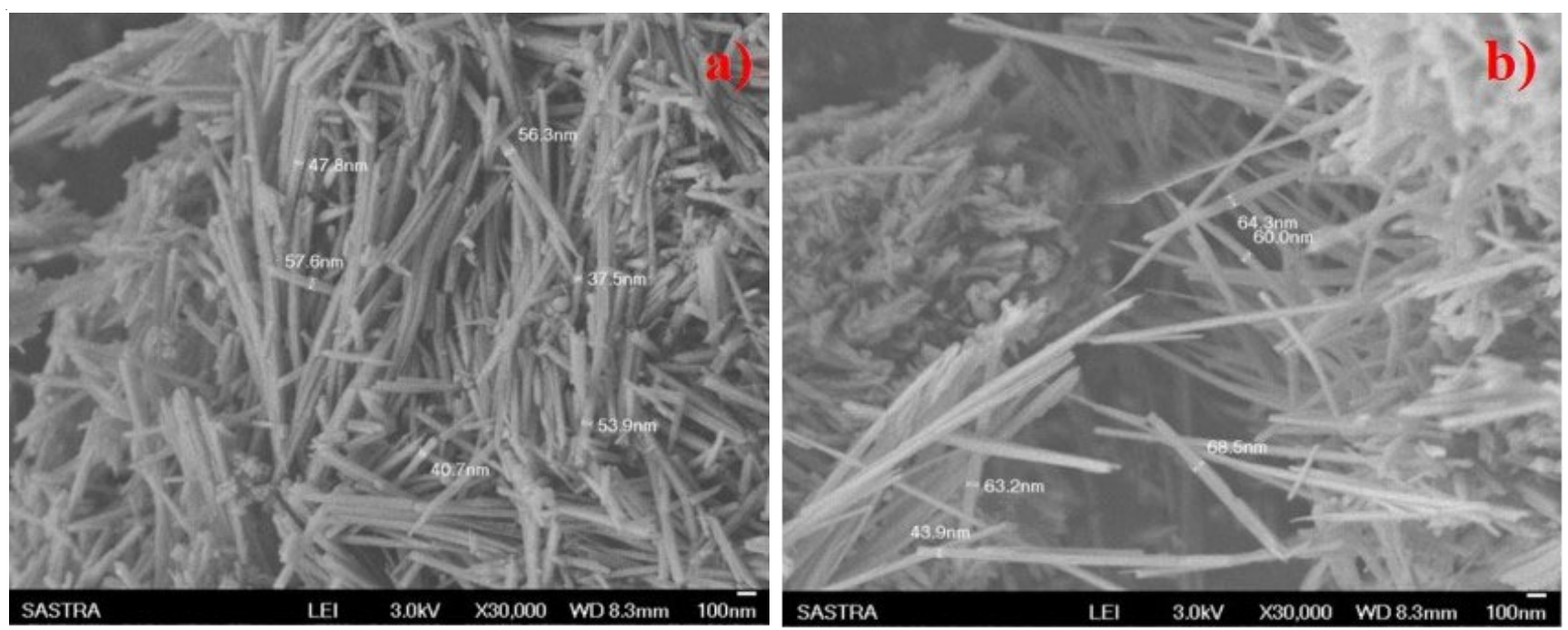

Fig. 3. (a) and (b) FESEM images of iron oxide nanoparticles 
4a. As expected, the peaks at around $0.8,6.3$ and $6.8 \mathrm{keV}$ are related to the binding energies of Fe [16]. The EDX analysis suggests that oxygen and iron are the major constituents in the synthesized iron oxide nanoparticles. The bar graph depicting elemental composition is represented in Fig. $4 \mathrm{~b}$.
High resolution transmission electron micrograph analysis (HRTEM): Fig. 5a-b showed the HRTEM images of iron oxide nanoparticles. Fig. 5a clearly indicated rod shaped morphology of iron oxide nanoparticles with an average particle length of $173.92 \mathrm{~nm}$ and average particle diameter of 30.26

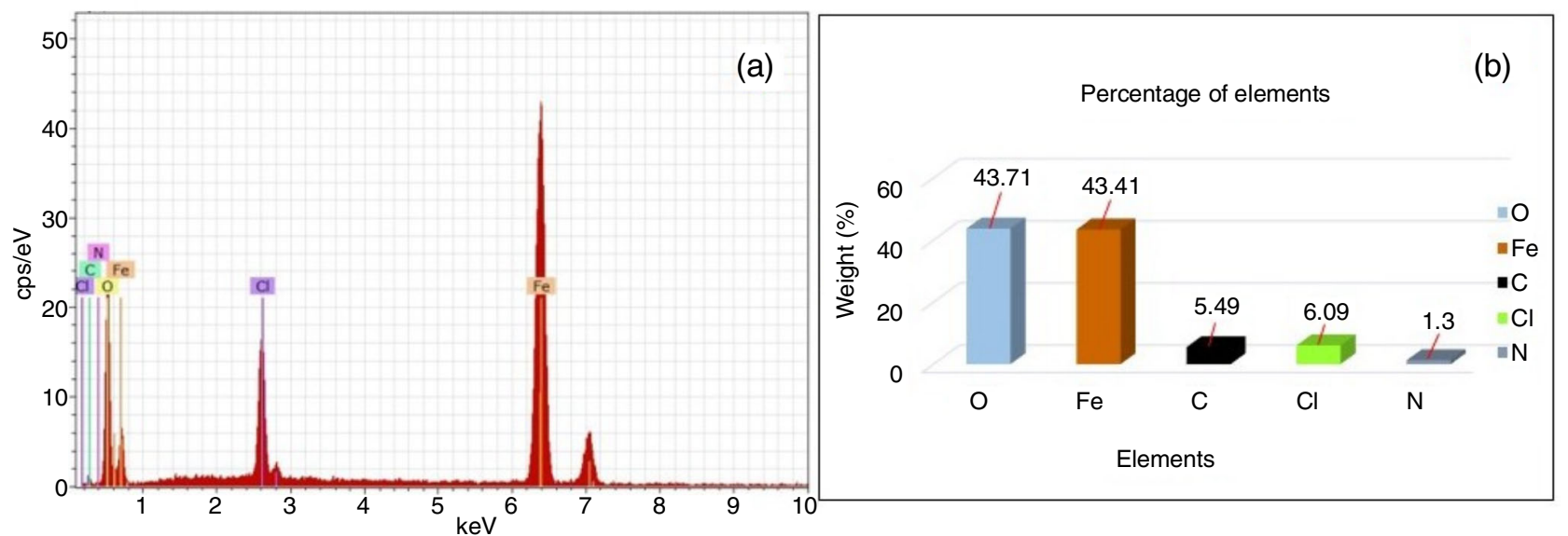

Fig. 4. (a) EDX spectrum of iron oxide nanoparticles (b) Bar graph for percentage of elements
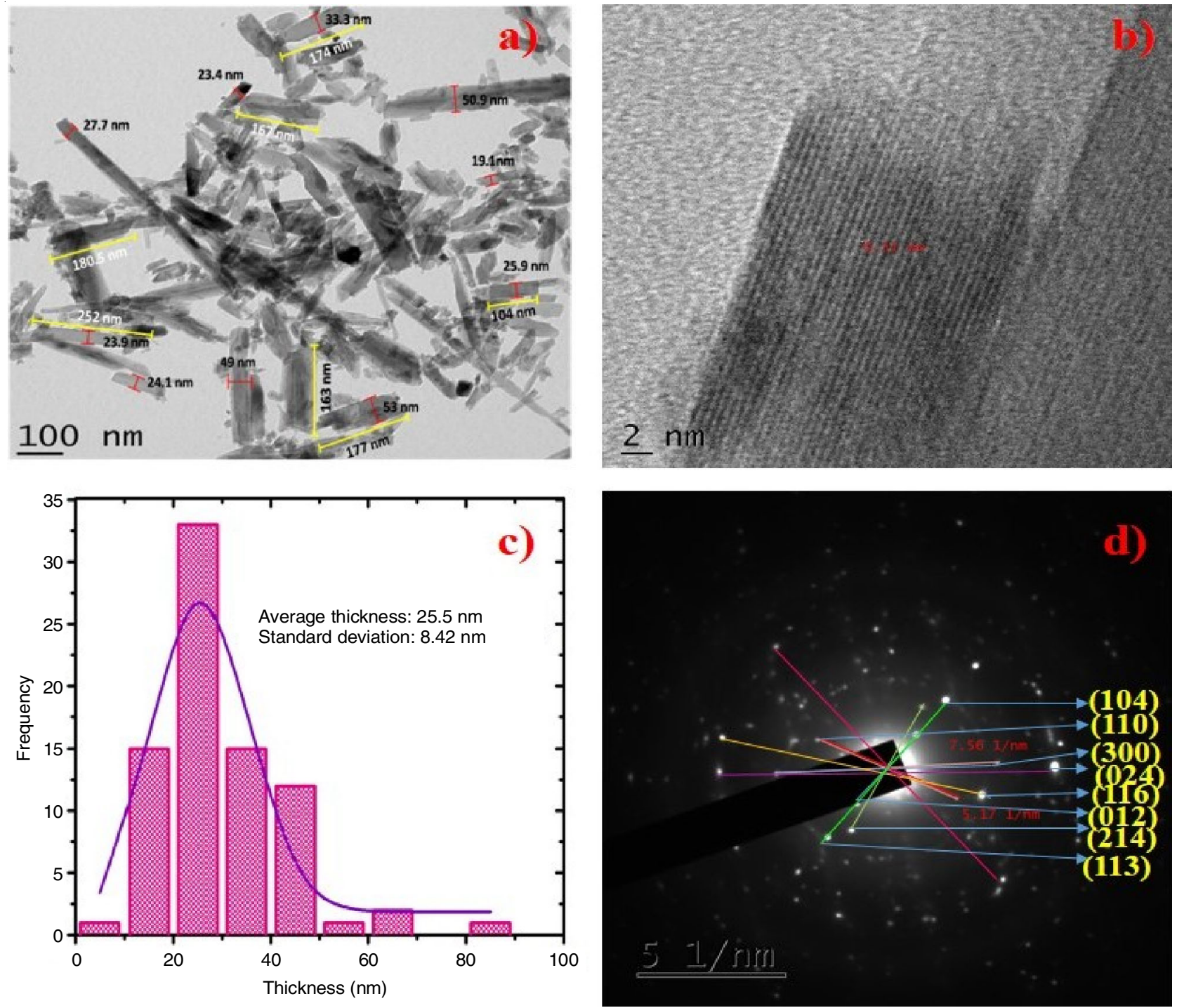

Fig. 5. (a) and (b) HRTEM images of iron oxide nanoparticles (c) Histogram obtained from TEM data (d) SAED pattern of iron oxide nanoparticles 
$\mathrm{nm}$. The bright field TEM image is shown in Fig. $5 \mathrm{~b}$. The fringes in the image are closely related to planes of atoms in the crystalline lattice. The particle size distribution histogram is shown in Fig. 5c. The average particle size thickness is $25.5 \mathrm{~nm}$ with the standard deviation of $8.42 \mathrm{~nm}$. The average particle size diameter obtained from HRTEM closely matches with the average grain size diameter obtained by FESEM analysis.

SAED pattern of iron oxide nanoparticles (Fig. 5d) showed bright spots which confirm the crystallinity of the synthesized nanomaterial. The $\mathrm{d}$ spacing and lattice plane obtained from SAED pattern matches well with the XRD data.

Vibrating sample magnetometer analysis (VSM): Fig. 6 shows the magnetization curve of iron oxide nanoparticles measured by sweeping the external magnetic field between \pm $15 \mathrm{kOe}$ at room temperature. The saturated magnetization (Ms) of iron oxide nanoparticles is $6.4270 \times 10^{-3} \mathrm{emu}$. The smaller Ms value may be due to the decrease in particle size and spin disorder at the surface. Both factors are significant for nanoparticles with large surface-to-volume ratio [12]. A hysteresis loop was observed with retentivity $(\mathrm{Mr}) 504.32 \times 10^{-6} \mathrm{emu}$, sensitivity $-4.4000 \mathrm{emu}$ and coercivity $398.61 \mathrm{G}$. The magnetic hysteresis loop thus obtained represents the ferromagnetic nature of the synthesized iron oxide nanoparticles.

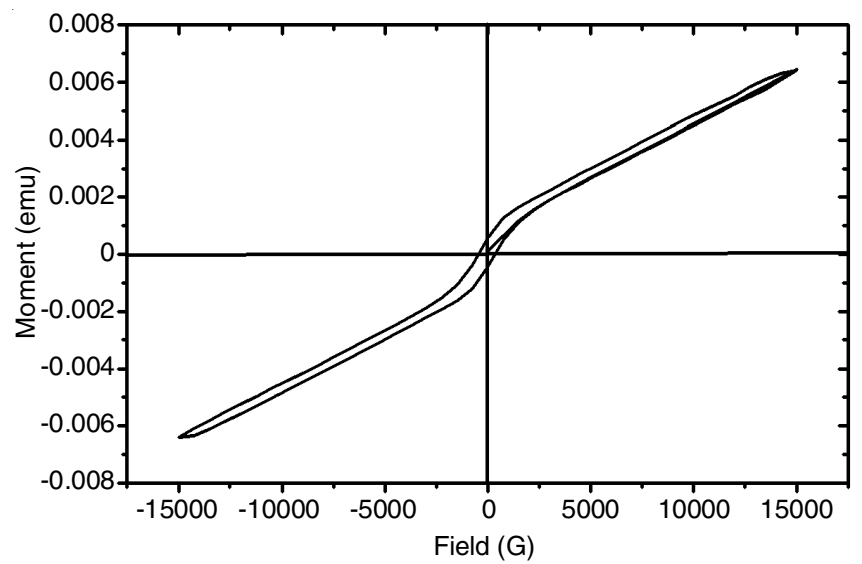

Fig. 6. Room temperature magnetization hysteresis loop of the iron oxide nanoparticles

Antibacterial activity: In current work, the antibacterial study of iron oxide nanoparticles in three different concentrations was tested against nine pathogenic bacteria using standard disc diffusion method. The antibacterial activities were compared with the activities of streptomycin (Fig. 7). The synthesized iron oxide nanoparticles showed positive antibacterial activity against Vibrio parahaemolyticus, Klebsiella pneumonia, Salmonella typhimurium and Staphylococcus aureus. As the concentration of nanoparticle increased the zone of inhibition increased. Antibacterial activity of iron oxide nanoparticles showed greater activity against Vibrio parahaemolyticus and Staphylococcus aureus. Iron oxide nanoparticles showed moderate activity against Salmonella typhimurium and Klebsiella pneumonia. Iron oxide nanoparticles showed no activity for the remaining bacterial pathogens. choline chloride, $\mathrm{D}(+)$-glucose and distilled water showed no activity against any pathogens. The results are shown in Table-1.

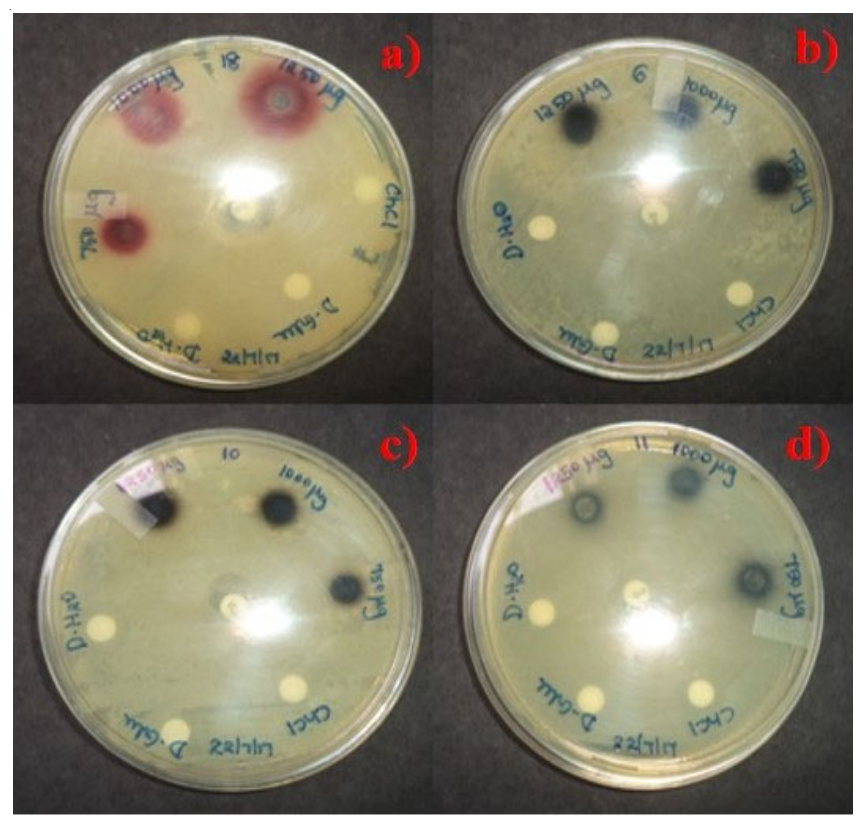

Fig. 7. Antibacterial activities of iron oxide nanoparticles in distilled water (1.25, 1 and $0.5 \mathrm{mg} / \mathrm{disc}$ ) against (a) Vibrio parahaemolyticus, (b) Klebsiella pneumonia, (c) Salmonella typhimurium and (d) Staphylococcus aureus

\section{Photocatalytic activity}

Absorption spectra analysis: The analysis of absorption spectra of Congo red is necessary to determine the Congo red adsorption equilibrium on the catalyst surface. Fig. 8 shows the change in absorption spectra of Congo red using $10 \mathrm{ppm}$

TABLE-1

ANTIBACTERIAL ACTIVITY OF S = STREPTOMYCIN, IONPS = IRON OXIDE NANOPARTICLES, ChCl = CHOLINE CHLORIDE, D-Glu $=\mathrm{D}(+)$ GLUCOSE AGAINST TEST ORGANISMS, DW $=$ DISTILLED WATER, $(-)=$ NO INHIBITION

\begin{tabular}{|c|c|c|c|c|c|c|c|}
\hline \multirow[b]{2}{*}{ Name of the organism } & \multicolumn{7}{|c|}{ Inhibition zone ( $\mathrm{mm}$ in diameter) } \\
\hline & $\begin{array}{l}\text { DW (20 } \\
\mu L / \text { disc) }\end{array}$ & $\begin{array}{c}S(25 \\
\mu \mathrm{g} / \text { disc })\end{array}$ & $\begin{array}{c}\text { IONPs (1.25 } \\
\text { mg/disc) }\end{array}$ & $\begin{array}{l}\text { HNRs (1 } \\
\text { mg/disc) }\end{array}$ & $\begin{array}{c}\text { HNRs (0.5 } \\
\text { mg/disc) }\end{array}$ & $\begin{array}{l}\mathrm{ChCl}(1 \\
\text { mg/disc) }\end{array}$ & $\begin{array}{l}\text { D-Glu (1 } \\
\text { mg/disc) }\end{array}$ \\
\hline Enterobacter aerogenes (111) & - & - & - & - & - & - & - \\
\hline Staphylococcus epidermidis (3615) & - & - & - & - & - & - & - \\
\hline Escherichia coli (25922) & - & 23 & - & - & - & - & - \\
\hline Vibrio parahaemolyticus (451) & - & 14 & 18 & 16 & 12 & - & - \\
\hline Proteus vulgaris (1771) & - & 10 & - & - & - & - & - \\
\hline Klebsiella pneumonia (ATCC1706) & - & 14 & 11 & 10 & 10 & - & - \\
\hline Yersinia enterocolitica $(840)$ & - & 17 & - & - & - & - & - \\
\hline Salmonella typhimurium (1251) & - & 12 & 12 & 11 & 10 & - & - \\
\hline Staphylococcus aureus (96) & - & 11 & 18 & 16 & 12 & - & - \\
\hline
\end{tabular}




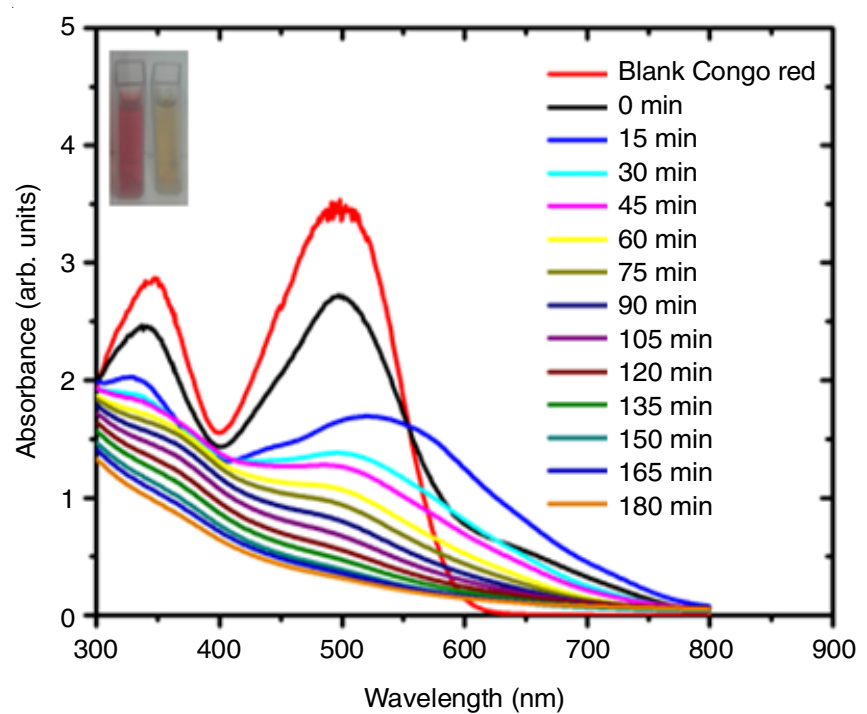

Fig. 8. Change in absorption spectra of Congo red (reaction condition: $100 \mathrm{~mL}$ of $10 \mathrm{ppm}$ dye $+2 \mathrm{~mL}$ of $30 \% \mathrm{H}_{2} \mathrm{O}_{2}+100 \mathrm{mg}$ HNRs under solar light irradiation for $180 \mathrm{~min}$ ) (Inset: Decolourization of Congo red)

Congo red $+2 \mathrm{~mL}$ of $30 \% \mathrm{H}_{2} \mathrm{O}_{2}+100 \mathrm{mg}$ iron oxide nanoparticles for $180 \mathrm{~min}$ under solar light irradiation. In presence of iron oxide nanoparticles and $\mathrm{H}_{2} \mathrm{O}_{2}$ there is gradual decrease in the optical density of the dye solution under solar light with increase in irradiation time. From $15 \mathrm{~min}$ solar light irradiation the major band of Congo red monomer at $497 \mathrm{~nm}$ is gradually shifted to $532 \mathrm{~nm}$. The decrease in intensity and the red shift of Congo red monomer band is due to the partially self-association of Congo red monomers as anionic dimers in face-toface arrangement to minimize their hydrophobic interaction with water molecule [17].

Percentage degradation analysis: The percentage degradation of dye is calculated using the following formula:

$$
\text { Degradation }(\%)=\frac{\mathrm{C}_{\mathrm{i}}-\mathrm{C}_{\mathrm{f}}}{\mathrm{C}_{\mathrm{i}}} \times 100
$$

where $\mathrm{C}_{\mathrm{i}}$ and $\mathrm{C}_{\mathrm{f}}$ are the initial and final dye concentrations, respectively.

Fig. 9 depicts the plot for photodegradation (\%) versus time interval for photodegradation of Congo red under solar light irradiation for $180 \mathrm{~min}$. A significant degradation of 88.24 $\%$ of Congo red was achieved in 180 min by using iron oxide nanoparticles $+\mathrm{H}_{2} \mathrm{O}_{2}$. The effect of electron acceptors using $\mathrm{H}_{2} \mathrm{O}_{2}$ improves the decolourization rate due to the formation of hydroxide radicals [9]. The combination of iron oxide nanoparticles, $\mathrm{H}_{2} \mathrm{O}_{2}$ and sunlight illumination played vital role in the effective photo degradation of Congo red.

Kinetic analysis: Kinetic plot of synthesized iron oxide nanoparticles on decolourization of Congo red is shown in Fig. 10. The results obtained were presented as a plot of $\ln (\mathrm{C} /$ $\mathrm{C}_{\mathrm{o}}$ ) versus time. A linear plot obtained indicated that photocatalytic degradation of iron oxide nanoparticles followed pseudo first-order kinetics.

\section{Conclusion}

The hematite nanorods synthesized using choline chloride: $\mathrm{D}(+)$-glucose deep eutectic solvent acted as a promising antibacterial material against disease causing clinical pathogens

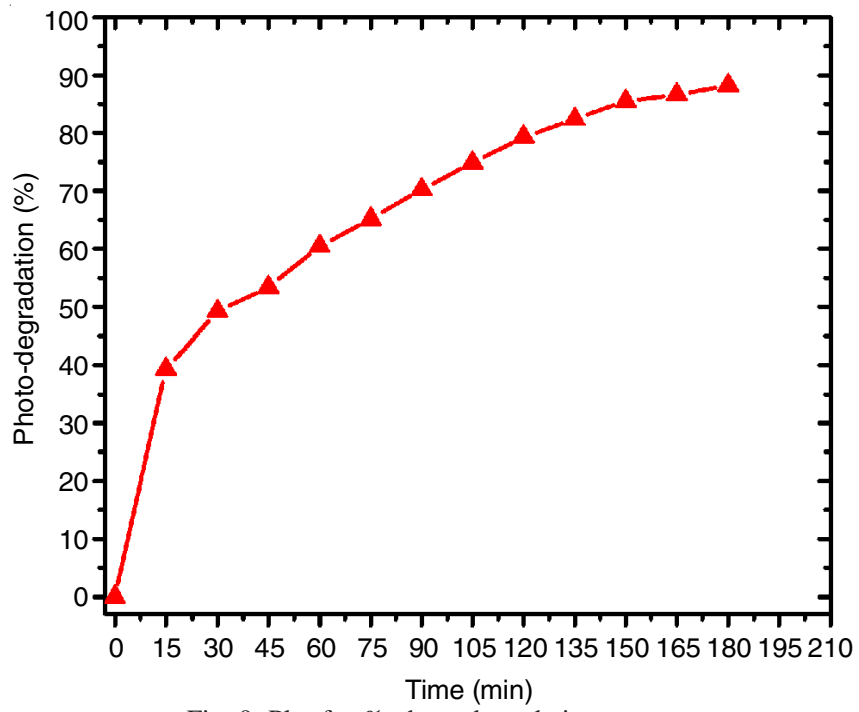

Fig. 9. Plot for $\%$ photo-degradation versus

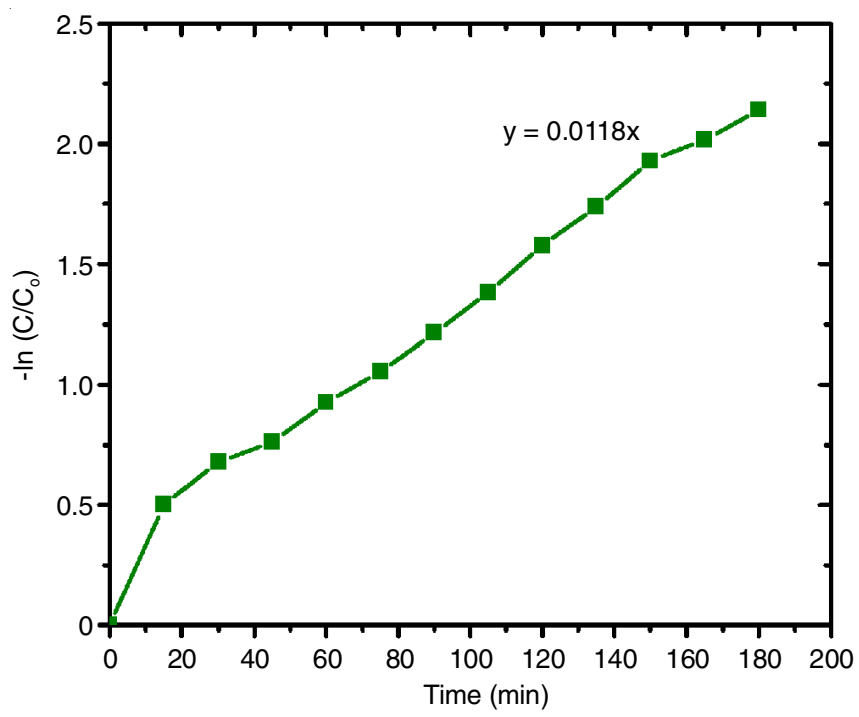

Fig. 10. Kinetic plot for decolourization of Congo red solar light irradiation time

such as Vibrio parahaemolyticus, Klebsiella pneumonia, Salmonella typhimurium and Staphylococcus aureus. The results suggested that hematite nanorods are highly capable of rendering antibacterial efficiency against both Gram positive and Gram negative pathogenic bacterial strains thus retaining potential application in pharmaceutical and biomedical industries. In addition to this, the synthesized hematite nanorods were used as an effective photo catalyst for the photocatalytic degradation of Congo red under sunlight condition. Addition of $\mathrm{H}_{2} \mathrm{O}_{2}$ enhanced the degradation rate. It was found that $88.24 \%$ photodegradation of Congo red was achieved in $180 \mathrm{~min}$. The present investigation revealed that the synthesized hematite nanorods can be used as an active photocatalyst in wastewater purification systems. The results confirmed that the synthesized hematite nanorods can be a potential nanomaterial for the environmental and biomedical applications.

\section{ACKNOWLEDGEMENTS}

The authors thank CRIST Lab Stella Maris College, Chennai; Loyola College, Chennai; IIT Madras; STIC, Cochin; and 
SASTRA University, Thanjavur, India for providing laboratory facilities. The authors also cordially thank Dr. P. Agastian S. Theoder, Department of Plant Biology \& Biotechnology, Loyola College, Chennai, India for the assistance in carrying out the antibacterial studies.

\section{CONFLICT OF INTEREST}

The authors declare that there is no conflict of interests regarding the publication of this article.

\section{REFERENCES}

1. M. Hayyan, T. Aissaoui, M.A. Hashim, M.A.H. AlSaadi and A. Hayyan, J. Taiwan Inst. Chem. Engin., 50, 24 (2015); https://doi.org/10.1016/j.jtice.2015.03.001.

2. A. Abo-Hamad, M. Hayyan, M.A.H. AlSaadi and M.A. Hashim, Chem. Eng. J., 273, 551 (2015); https://doi.org/10.1016/j.cej.2015.03.091.

3. S. Bagheri, K.G. Chandrappa and S.B.A. Hamid, Res. J. Chem. Sci., 3, 62 (2013).

4. W.F. Schmidt and S. Singh, J. Nanosci. Nanotechnol., 14, 1 (2014); https://doi.org/10.1166/jnn.2014.9265.

5. S.S. Behera, J.K. Patra, K. Pramanik, N. Panda and H. Thatoi, World J. Nano Sci. Engin., 2, 196 (2012); https://doi.org/10.4236/wjnse.2012.24026.
6. S.A. Mahdy, Q.J. Raheed and P.T. Kalaichelvan, Int. J. Modern Eng. Res., 2, 578 (2012).

7. M. Mohopatra and S. Anand, Int. J. Eng. Technol., 2, 127 (2010).

8. K.M. Reza, A. Kurny and F. Gulshan, Int. J. Environ. Sci. Dev., 7, 325 (2016); https://doi.org/10.7763/IJESD.2016.V7.793.

9. M.I. Kim, J.S. Im, S.J. In, H. Kim, J.G. Kim and Y.S. Lee, Carbon Lett., 9, 195 (2008); https://doi.org/10.5714/CL.2008.9.3.195.

10. M.A. Rauf and S.S. Ashraf, Chem. Eng. J., 151, 10 (2009); https://doi.org/10.1016/i.cej.2009.02.026.

11. A. Hayyan, F.S. Mjalli, I.M. AlNashef, Y.M. Al-Wahaibi, T. Al-Wahaibi and M.A. Hashim, J. Mol. Liq., 178, 137 (2013); https://doi.org/10.1016/j.molliq.2012.11.025.

12. F. Chen, S. Xie, J. Zhang and R. Liu, Mater. Lett., 112, 177 (2013); https://doi.org/10.1016/j.matlet.2013.09.022.

13. P. Pavendan and C.S. Rajasekaran, Int. J. PharmTech. Res., 4, 476 (2012).

14. F.N. Sayed and V. Polshettiwar, Scient. Rep., 5, 09733 (2015); https://doi.org/10.1038/srep09733.

15. T. Wang, S. Zhou, C. Zhang, J. Lian, Y. Liang and W. Yuan, New J. Chem., 38, 46 (2014); https://doi.org/10.1039/C3NJ01060K.

16. M. Mahdavi, M.B. Ahmad, M.J. Haron, F. Namvar, B. Nadi, M.Z.A. Rahman and J. Amin, Molecules, 18, 7533 (2013); https://doi.org/10.3390/molecules18077533.

17. L. Nadjia, F. Abdelkader and B. Ahmed, J. Chem. Eng. Process Technol., 2, 1 (2011); https://doi.org/10.4172/2157-7048.1000108. 